\title{
Anatomical Course Demarcating the Safe Area for the Superior Gluteal Nerve
}

\author{
Simon Lammy*
}

\begin{abstract}
Iatrogenic injury to the superior gluteal nerve (SGN) persists despite a safe area being defined. Current descriptions of the course of the SGN are conflicting and do not provide agreeable distances to surface landmarks that are useful for most health care professionals. This study aimed to suggest a more conservative and gender-dependent estimate of the safe area between each buttock and genitals as defined by four bony surface landmarks. The posterior and lateral surfaces of each buttock in eight cadavers, four male and four female, were dissected. The surface anatomy of sixteen SGNs was defined in relation to the quadrate tubercle of the intertronchanteric crest of the femur (QTIF), the most cranial ridge of the iliac crest (IC), the anterior superior iliac spine (ASIS) and the posterior superior iliac spine (PSIS). Between the sexes, no significant difference existed concerning average SGN lengths across each buttock pair, (i.e. SGN length male/female difference $\mathrm{df}=3(\mathrm{p}=\mathbf{0 . 2 7 3})$; Pearson $=-$ 0.76). There was no significant difference between both buttock sides concerning the SGN distances from each of the four bony surface landmarks across either sex (e.g. male QTIF $d f=3$ ( $p=0.284)$; Pearson correlation $=\mathbf{- 0 . 3 1}$.) From our measurements we conclude that the standard safe area is too generous and should be half the size immediately adjacent to the tip of the greater trochanter.
\end{abstract}

KEYWORDS: Superior gluteal nerve (SGN); greater tronchanter; safe area; injury

\section{INTRODUCTION}

Injury to the superior gluteal nerve (SGN) can be caused by fractures, penetrating wounds and diseases due to posterior hip dislocations, surgery and poliomyelitis which damage the lumbosacral roots and various portions of the lumbosacral plexus. Nerve ischaemia, intravenous drug abuse, hypotension, entrapment within the piriformis muscle, lumbar lordosis, inadequate back stabilization, falls, hip arthroplasty, and particularly, needle injections, can also produce SGN damage $(1,2)$.

The SGN is responsible for abduction, flexion, medial rotation, extension and lateral rotation about the hip joint through both the gluteus medius and gluteus minimus muscles. While injury to the SGN normally

\footnotetext{
*To whom correspondence should be addressed:

Simon Lammy

92 Mallinson Road

Battersea

London

SW11 1BN

Email: s.lammy@ucl.ac.uk
}

occurs in association with other injuries to the pelvic region, isolated SGN injury has been reported especially after needle and blunt trauma and surgical procedures (3). Sciatic nerve injury, which can manifest as paralytic drop foot and gluteal fibrosis, is seen clinically as external rotation and abduction contracture of the hip, being complications of intragluteal injections during infancy (4). The sciatic nerve is in particular danger when using a transgluteal incision (5). This occurs despite injections being made within the safe area as defined by Jacobs and Buxton, who identified the safe area to be five centimetres adjacent to the greater trochanter based on ten bilateral cadaveric dissections (6). Iatrogenic manipulation remains a significant cause of SGN injury (manifested by decreased hip abduction, an externally rotated leg and a positive Trendelenburg sign) and cannot be rendered historically obsolete by the $50 \mathrm{~mm}$ safe area.

Against this background of injury to the SGN as a result of injections into the 'safe area', the present study was undertaken to document the course of the SGN in relation to surface anatomical landmarks and to define 


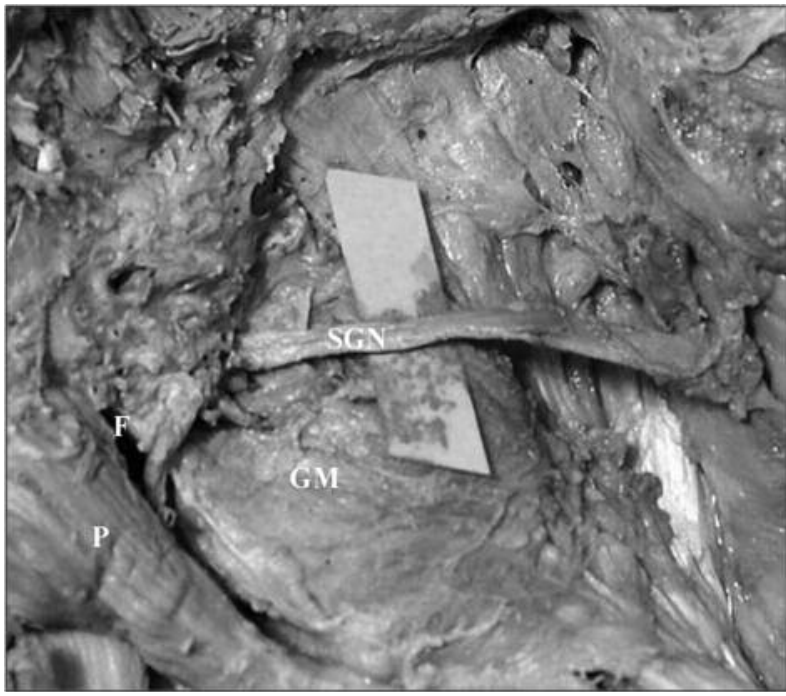

Figure 1: Dissection of the Right Buttock - Right endopelvic dissection of the superior gluteal nerve (SGN) demonstrating its course once exiting the suprapiriformis foramen $(\mathrm{F})$ and its relation to the gluteus minimus (GM) and piriformis (P) muscles.

the extent of its variability between sides and between sexes.

\section{METHODS}

Dissections were undertaken of four male and four female cadavers (mean age: 75 years; range: 60-90). The course of the SGN was documented bilaterally relative to four major bony surface landmarks: quadrate tubercle of the intertronchanteric crest of the femur (QTIF); most cranial ridge of the iliac crest (IC); anterior superior iliac spine (ASIS); posterior superior iliac spine (PSIS).

Dissections were carried out with the cadavers in the prone position (see Fig1). The surface incisions encompassed a rectangle enclosing the entire buttock, removing skin and subcutaneous tissue. The gluteus maximus was then removed and reflected laterally. The gluteus medius was dissected and reflected anterolaterally and superiorly to expose the SGN.

The SGN was dissected so that it was separated from surrounding muscle tissue and from the superior gluteal vasculature, but it remained anchored at its suprapiriformis origin and at its terminations in gluteus medius, minimi and tensor fascia. The portion of the SGN that came nearest to the 'safe area' corresponded to the caudal SGN segment and the relations of this segment were therefore defined in detail.

The caudal SGN was measured from the suprapiriformis foramen to the point of its muscle termination. We also measured the distance from its point of termination to the four bony surface landmarks described above (i.e. QTIF; IC; ASIS; PSIS.) The angle of deviation of the SGN from a lateral line passing through both suprapiriformi of the greater sciatic foramina was also measured to gauge precisely its course relative to the bony surface landmarks.

The significance of differences between means was determined using the 2-tailed T-test and the correltation between data sets was determined using the Pearson method.

\section{RESULTS}

No scarring around the gluteal region, suggestive of previous trauma, was seen on any cadaver. In all instances the SGN exited from the posterior aspect of the pelvis through the suprapiriformis foramen (i.e. above the piriformis muscle.) The SGN together with the superior gluteal artery and vein was sheathed and bound by an aponeurosis located between the gluteus medius and gluteus minimis. The SGN then entered the gluteus medius before branching to produce several branches that terminated within gluteus medius, gluteus minimis and tensor fascia latae.

Quantitative data is shown in Table 1. In summary, the following features were noted: the SGN was on average longer in the left buttock for both sexes but was deflected upward/downward dependant on the sex (i.e. male left upward/right downward; female left downward/right upward.) Although SGN length was longer in the males and had a greater upward deflection this was not statistically significant (i.e. accounting for average height/weight/width sex differences.)

For male cadavers, significant right-left differences were found for caudal SGN length (i.e. $60+/-8.2 \mathrm{~mm}$ vs $78+/-8.2 \mathrm{~mm}, \mathrm{df}=3, \mathrm{p}=0.035, \mathrm{n}=4$; Pearson correlation $=0.65$ ) but not for SGN angle between both sides (i.e. $\downarrow 3.8+/-\uparrow 10.4^{\circ}$ vs $7.5+/-33.2^{\circ}, \mathrm{df}=3, \mathrm{p}=0.170, \mathrm{n}=4$; Pearson correlation $=0.80$.) For female cadavers, there was no significant difference concerning SGN length (i.e. $49+/-12.9 \mathrm{~mm}$ vs $65+/-8.5 \mathrm{~mm}, \mathrm{df}=3, \mathrm{p}=0.061$, $\mathrm{n}=4$; Pearson correlation $=0.53$ ) and $\mathrm{SGN}$ angle (i.e. $\downarrow 3.8+/-6.5^{\circ}$ vs $6.3+/-\uparrow 10.8^{\circ}, \mathrm{df}=3, \mathrm{p}=0.236, \mathrm{n}=4$; Pearson correlation $=0.71$ ) between each buttock side.

For male cadavers there was a significant difference concerning length and resultant angle on both sides (i.e. left buttock $\mathrm{df}=3(\mathrm{p}=0.018)$; Pearson correlation = 0.55 ; right buttock $\mathrm{df}=3$ ( $\mathrm{p}=0.008)$; Pearson correlation $=0$.) For female cadavers a significant difference also existed concerning length and resultant angle on both sides also (i.e. left buttock $\mathrm{df}=3(\mathrm{p}=0.012)$; Pearson correlation $=-0.31$; right buttock $\mathrm{df}=3 \quad(\mathrm{p}=0.011)$; Pearson correlation $=-0.29$.)

A significant difference also occurred between the calculated average SGN length across each buttock pair and the calculated average SGN angle across each buttock pair (i.e. average SGN length across each buttock pair vs. average SGN angle across each buttock pair: male cadavers $\mathrm{df}=3(\mathrm{p}=0.014)$; Pearson correlation 
$=-0.54$; female cadavers $\mathrm{df}=3 \quad(\mathrm{p}=0.001)$; Pearson correlation $=-0.31$.)

Between the sexes, no significant difference existed concerning average SGN lengths across each buttock pair and average angle across each buttock pair (i.e. SGN length male/female difference $\mathrm{df}=3 \quad(\mathrm{p}=0.273)$; Pearson $=-0.76$; SGN angle male/female difference $\mathrm{df}=3(\mathrm{p}=0.728)$; Pearson $=0.07$. $)$

There was no significant difference between both buttock sides concerning the SGN distances from each of the four bony surface landmarks across either sex (e.g. male QTIF $\mathrm{df}=3$ ( $\mathrm{p}=0.284)$; Pearson correlation $=$ -0.31.)

However, there was a noticeable but not significant difference concerning distance from the QTIF for both male and female cadavers.

\section{DISCUSSION}

The SGN surfaces from the ventral branches of L4, L5, S1, L2 and the posterior surface of the lumbosacral plexus $(1,7)$. It is commonly accepted that the greater part of the nerve fibres come from the lumbosacral trunk, particularly from L5, conveying motor fibres intended for the gluteus medius, gluteus minimis and tensor fasciae latae muscles (7). No sensory fibres course through the SGN (1).

The SGN courses through spaces adjacent to both the gluteus medius and gluteus minimis after it has exited the suprapiriformis foramen. Occassionally neurofibres of the SGN did pierce the piriformis muscle en route to their final termination. But on no occasion did the main body of the nerve course through the piriformis muscle. The nerve, although distinct, is entwined within the superior neurovascular bundle amongst the superior gluteal arteries and veins. Shrouded by an aponeurosis the superior neurovascular bundle is visually distinct within the aforementioned space. The SGN generally courses horizontally and anteriorly. Concerning upward or downward deflection we agree with Ramesh et al., that there is no significant difference (8).

The elaborate pattern described by Jacobs and Buxton produced by branching of the SGN was not studied but only the nerves gross course relative to the four major bony landmarks (i.e. therefore trying to simulate the accuracy of surgical incisions guided only by major bony landmarks) (6).

The difference concerning SGN length between buttock sides was also reflected in the nerves physical characteristics (i.e. thicker on the left side) which may be dependant upon whether subject footedness (e.g. standing predominantly with a lean toward the left side; kicking a football with the right foot whilst being stabilised by the left leg.)

We agree with Duparc et al., and Perez et al., that the greater tronchanter is a reliable indicator of the general course of the SGN $(9,10)$, particularly the caudal branch, because of its ease of access when evaluating where to inject or incise the gluteal region. But our measured distances from the most caudal SGN branch to the greater trochanter is not consistent with most previous studies: Duparc et al., (i.e. range $40-65 \mathrm{~mm}$; average $51.25 \mathrm{~mm}$ ) Perez et al., (i.e. $20 \mathrm{~mm}$ ) Bos et al., (i.e. $30 \mathrm{~mm}$ ) Nazarian et al., (i.e. $30-50 \mathrm{~mm}$ ) Foster and Hunter (i.e. average $78.2 \mathrm{~mm}$; range $63-84 \mathrm{~mm}$ ) (see table 1.) (5,9-12). Baker and Bitounis cadaveric study discovered that the inferior branch of the SGN might be as close to the tip of the greater trochanter as $30 \mathrm{~mm}$ in the anterior angle and $60-80 \mathrm{~mm}$ in the posterio-superior

\begin{tabular}{|c|c|c|c|c|c|c|c|c|c|c|c|c|}
\hline \multirow[b]{2}{*}{ Sex } & \multicolumn{2}{|c|}{$\begin{array}{c}\text { Superior Gluteal } \\
\text { Nerve Length } \\
\text { (mm) }\end{array}$} & \multicolumn{2}{|c|}{$\begin{array}{l}\text { Angle Deviation } \\
\text { from Horizontal }\end{array}$} & \multicolumn{2}{|c|}{$\begin{array}{l}\text { Length from } \\
\text { Greater } \\
\text { Tronchanter } \\
\text { (mm) }\end{array}$} & \multicolumn{2}{|c|}{$\begin{array}{l}\text { Length from Iliac } \\
\text { Crest }(\mathrm{mm})\end{array}$} & \multicolumn{2}{|c|}{$\begin{array}{c}\text { Length from } \\
\text { Anterior Superior } \\
\text { lliac Spine }(\mathrm{mm})\end{array}$} & \multicolumn{2}{|c|}{$\begin{array}{l}\text { Length from } \\
\text { Posterior } \\
\text { Superior Iliac } \\
\text { Spine (mm) }\end{array}$} \\
\hline & L & $\mathrm{R}$ & L & $\mathrm{R}$ & L & $\mathrm{R}$ & L & $\mathrm{R}$ & $\mathrm{L}$ & $\mathrm{R}$ & L & $\mathrm{R}$ \\
\hline $\begin{array}{l}\text { Male } \\
\text { Average } \\
\text { Length }\end{array}$ & 78 & 60 & $\uparrow 7.5$ & $\downarrow 3.8$ & 60 & 44 & 95 & 100 & 95 & 85 & 95 & 95 \\
\hline $\begin{array}{l}\text { Standard } \\
\text { Deviation }\end{array}$ & 8.2 & 8.2 & 33.2 & 10.4 & 23.1 & 4.8 & 17.3 & 14.1 & 19.2 & 12.9 & 5.8 & 23.8 \\
\hline Range & 30 & 20 & 40 & 45 & 40 & 10 & 40 & 30 & 40 & 30 & 10 & 50 \\
\hline $\begin{array}{l}\text { Female } \\
\text { Average } \\
\text { Length }\end{array}$ & 65 & 49 & $\downarrow 6.3$ & $\uparrow 3.8$ & 35 & 53 & 105 & 95 & 70 & 50 & 105 & 90 \\
\hline $\begin{array}{l}\text { Standard } \\
\text { Deviation }\end{array}$ & 12.9 & 8.5 & 10.8 & 6.5 & 30 & 33 & 19.2 & 20.8 & 14.1 & 21.6 & 5.8 & 11.6 \\
\hline Range & 30 & 20 & 45 & 25 & 60 & 80 & 40 & 50 & 30 & 50 & 10 & 20 \\
\hline
\end{tabular}

Table 1: Measurement Refining the Safe Area - Length and distance from the four bony surface landmarks and angle from a lateral line passing through both suprapiriformi of the greater sciatic foramina ( $\uparrow$ denotes upward course of SGN relative to the lateral line $/ \downarrow$ denotes downward course of SGN relative to the lateral line). 
angle (13). The above variations can be explained due to differences in anatomical dissection techniques; position and preservation state of the cadavers; choice of most caudal branch; integrity of the gluteus medius muscle during dissection (5).

The major implication is that the adjacent $50 \mathrm{~mm}$ safe area as proposed by Jacobs and Buxton, although they mention that extra care should be taken in short patients in whom branches of the SGN could reside within the safe area and now contradicted towards the reverse by Bos et al., is consistent with the above results $(5,6)$. However, this is not consistent with the range of the other conducted investigations into the course of the SGN (e.g. Bos et al., found an inferior branch $10 \mathrm{~mm}$ closer to the greater trochanter) (5).

We conclude that the safe area as defined by Jacobs and Buxton is too generous (6). A safer area that is half this size should be employed (i.e. right adjacent to the tip of the greater trochanter).

\section{ACKNOWLEDGEMENTS}

Thanks to Dr. Wendy Birch, the Department of Anatomy \& Developmental Biology and the staff at the anatomy dissection room at UCL Medical School.

\section{REFERENCES}

1. Donofrio PD, Bird SJ, Assimos DG, Mathes DD. Iatrogenic superior gluteal mononeuropathy. Muscle Nerve 1998; 21(12):1794-6.

2. Kenny P, O'Brien CP, Synnott K, Walsh MG. Damage to the superior gluteal nerve after two different approaches to the hip. J Bone Joint Surg Br. 1999; 81(6):979-81.
3. Johnson EW, Raptou AD. A study of intragluteal injection. Arch Phys Med Rehabil. 1965; 46:167-77.

4. Napiontek M, Ruszkowski K. Paralytic drop foot and gluteal fibrosis after intramuscular injections. J Bone Joint Surg Br. 1993; 75(1):83-5.

5. Bos JC, Stoeckart R, Klooswijk AI, van Linge B, Bahadoer R. The surgical anatomy of the superior gluteal nerve and anatomical radiologic bases of the direct lateral approach to the hip. Surg Radiol Anat. 1994 ; 16(3):253-8.

6. Jacobs LG, Buxton RA. The course of the superior gluteal nerve in the lateral approach to the hip. J Bone Joint Surg Am. 1989; 71(8):1239-43.

7. Diop M, Parratte B, Tatu L, Vuillier F, Faure A, Monnier G. Anatomical bases of superior gluteal nerve entrapment syndrome in the suprapiriformis foramen. Surg Radiol Anat. 2002; 24(3-4):155-9.

8. Ramesh M, O'Byrne JM, McCarthy N, Jarvis A, Mahalingham $\mathrm{K}$, Cashman WF. Damage to the superior gluteal nerve after the Hardinge approach to the hip. J Bone Joint Surg Br. 1996; 78(6):903-6.

9. Duparc F, Thomine JM, Dujardin F, Durand C, Lukaziewicz M, Muller JM, Freger P. Anatomic basis of the transgluteal approach to the hip-joint by anterior hemimyotomy of the gluteus medius. Surg Radiol Anat. 1997; 19(2):61-7.

10. Perez MM, Llusa M, Ortiz JC, Lorente M, Lopez I, Lazaro A, Perez A, Gotzens V. Superior gluteal nerve: safe area in hip surgery. Surg Radiol Anat. 2004; 26(3):225-9.

11. Nazarian S, Tisserand P, Brunet C, Muller ME. Anatomic basis of the transgluteal approach to the hip. Surg Radiol Anat. 1987; $9(1): 27-35$.

12. Foster DE, Hunter JR. The direct lateral approach to the hip for arthroplasty. Advantages and complications. Orthopedics 1987; 10(2):274-80.

13. Baker AS, Bitounis VC. Abductor function after total hip replacement. An electromyographic and clinical review. J Bone Joint Surg Br. 1989; 71(1):47-50.

Simmon Lammy is a final year medical student at UCL Medical School maintaining anatomical research interests combined to medical educational advancement. 